\title{
A Study of Evaluating Organizational Performance Based on Balanced Scoresheet Viewpoint
}

\author{
Cheng-Wen Lee ${ }^{1}$ and Chin Kun Chang ${ }^{2}$
}

\begin{abstract}
Enterprise organizational performance refers to the number, quality, efficiency and profitability of tasks completed by individual members of an organization in a certain period of time. The realization of enterprise organizational performance should be based on the realization of individual performance, but the realization of individual performance does not necessarily guarantee that the enterprise organization has performance. If the performance of an enterprise organization is broken down to every job and every person according to a certain logical relationship, as long as each person meets the requirements of the enterprise organization, the performance of the enterprise organization can be achieved. The balanced scorecard (BSC) is a well-designed indicator system according to the strategic requirements of the enterprise organization. According to Kaplan and Norton, BSC is a tool for performance management. The management tools of its business strategy measure the business situation of the enterprise from four aspects: finance, customers, internal process of the enterprise, learning and growth, so as to improve the organizational performance, from a to a + , towards the long-term development of the enterprise. It decomposes the strategic objectives of the enterprise into various specific and balanced performance evaluation index systems, and evaluates the realization of these evaluation indexes in different periods of time, and continuously modifies and improves them, so as to establish a reliable basis for the completion of the strategic objectives of the enterprise. Therefore, this study explores the use of BSC in business management strategy framework, through the logical analysis of experts and scholars, to find out the appropriate criteria; to establish a complete business management system, so as to contribute to the operation of business strategy for improving organizational performance, establishing customer value, and making the business sustainable.
\end{abstract}

\footnotetext{
${ }^{1}$ Department of International Business, Chung Yuan Christian University, Taoyuan City, Taiwan.

${ }^{2}$ College of Business, Chung Yuan Christian University, Taoyuan City, Taiwan.
} 
JEL classification numbers: D23, C52, K32.

Keywords: Organizational Performance, Balanced Scorecard, Operation.

\section{Introduction}

Regarding the development process of Balanced Scorecard (BSC), the first generation of performance measurement only focuses on the financial aspect, and the second generation of performance measurement adds the measurement of intangible assets, such as product development and design, customer relationship, employee education and training, marketing information, enterprise knowledge management, etc. In 1998, more than $75 \%$ of the market value of S\&P 500 came from intangible assets. Its development history is 1990 research project -- the future measurement method of organizational performance. 12 enterprises participated in the research and development jointly by Harvard professor Robert Kaplan and executive director of Nolan Norton Institute Davie Norton. BSC was published in 1992; BSC practice was published in 1993 [1]; BSC application in strategic management system was published in 1996; and strategic application of enterprises was published in 2000 [2].

$\mathrm{BSC}$ is a well-designed indicator system according to the strategic requirements of the enterprise organization. According to Kaplan and Norton, BSC is a tool of performance management. It decomposes the strategic objectives of the enterprise into various specific and balanced performance evaluation index systems, and evaluates the realization of these indexes in different periods, so as to establish a reliable basis for the implementation of the strategic objectives of the enterprise. $\mathrm{BSC}$ is an indicator designed according to the conditions of the business strategy of an enterprise to evaluate its performance [3]. It is a tool of performance management according to the aspects of finance, customer, internal process, learning and growth. It decomposes the strategic objectives of enterprise management layer by layer into a variety of specific and mutually balanced performance evaluation indicators, and evaluates the realization of these indicators in different periods, and communicates with the performance evaluators to achieve sustainability (Figure 1). 


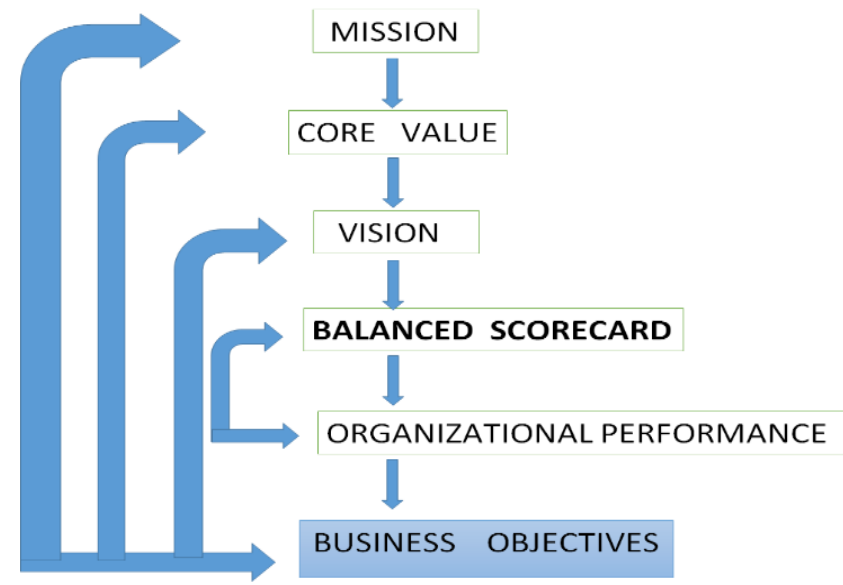

\section{Figure 1: The Role of Balanced Scorecard in Strategic Planning}

Essential characteristics of BSC (Figure 2):

1) BSC is a systematic strategic management system, which is based on system theory. BSC is a core tool for strategic management and implementation [4]. It is a strategic management and implementation system that effectively combines the goals, guidelines and initial action plans of the four perspectives through design and Implementation on the basis of reaching consensus on the overall development strategy of the enterprise. Its main purpose is to transform the strategy of an enterprise into specific actions, so as to create the competitive advantage of an enterprise.

2) BSC is an advanced tool for performance measurement. BSC divides the strategy into four different operational objectives, and designs appropriate performance measurement indicators according to these four perspectives. Therefore, it not only provides enterprises with all kinds of information necessary for effective operation, but also overcomes the interference of the complexity and asymmetry of information. What's more, the indicators it provides enterprises with are quantifiable, measurable and evaluable, which is more conducive to the comprehensive and systematic monitoring of enterprises and to the achievement of enterprise strategy and vision [4].

3) $\mathrm{BSC}$ as a communication tool. It is the most basic and powerful feature of the whole system. A well-designed, clear and effective performance indicator that clearly describes your assigned strategy and brings the abstract vision and strategy to life. According to the survey, before the implementation of the balanced scorecard, less than $50 \%$ of people said they knew and understood the strategy of the enterprise organization. One year after the implementation of the balanced scorecard, the proportion rose to $87 \%$.

4) Balance the causal relationship between scorecard performance indicators. The difference between balanced scorecard and other performance management systems lies in the focus on causality. 


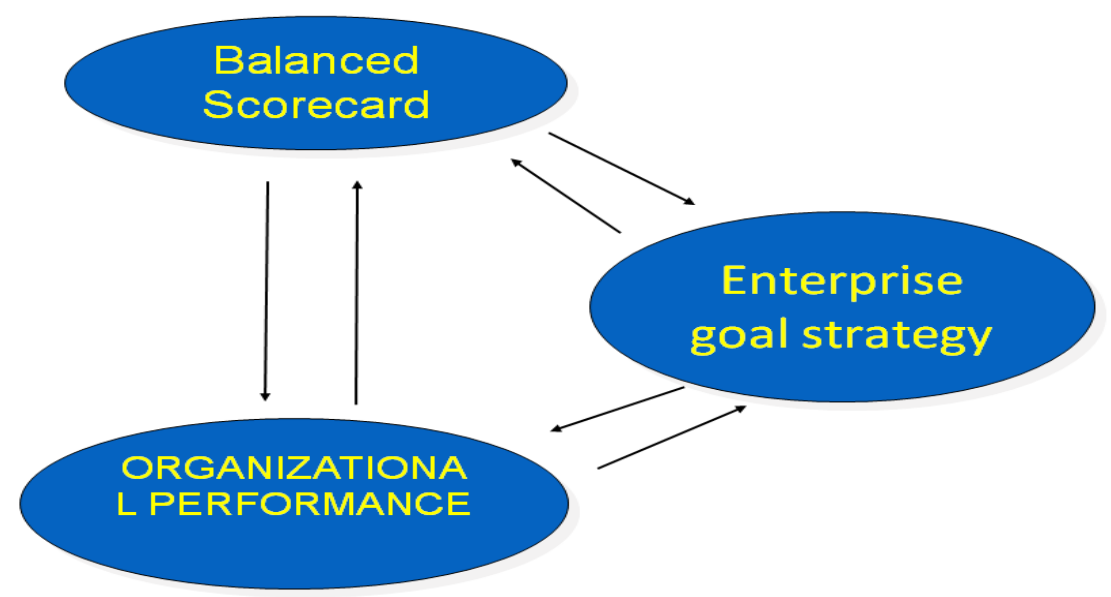

Figure 2: The Relationship between BSC, Organizational Performance and Corporate Goals

\section{Literature Review}

In the early 1990s, the balanced scorecard was a performance evaluation system of "future organizational performance measurement method", which was developed by Robert Kaplan of Harvard Business School, director of Nolan Norton Institute, founder and President of Renaissance global strategy group, David Norton. At that time, the purpose of the plan was to find a new organizational performance management method, which was developed by transcending the traditional performance evaluation model based on financial measurement, so that the organization's "strategy" could be transformed into "action". Since its establishment, balanced scorecard has aroused great interest and repercussions in the theoretical and customer circles in the world, especially in the United States and Europe [6].

BSC has been rated as one of the most influential management tools in 75 years by Harvard Business Review, which breaks the traditional single method of using financial indicators to measure performance. On the basis of financial indicators, the future driving factors, namely customer factors, internal business management process and employee learning and growth, play a very important role in the strategic planning and implementation management of the group. According to the explanation, the Balanced Scorecard mainly realizes the strategic planning through charts, cards and tables. Organizational performance evaluation is a general evaluation of the overall operation effect of an organization by managers using a certain index system. Effective evaluation can reveal the organization's operation ability, debt paying ability, profitability and contribution to society, provide relevant information for managers and stakeholders, and point out the direction for improving organizational performance.

The evaluation of organizational performance needs to select certain indicators, which, as the standard of measuring organizational performance, must reflect the 
comprehensive requirements for organizational management. From the perspective of organizational development process, a systematic and orderly evaluation feedback system plays an important role in the survival and development of an organization. However, it is difficult to evaluate organizational performance from different perspectives.

Stanley E. Seashore believes that the goals of most organizations are not single, but diverse, and some of them are conflicting [7,8]. If the ultimate goal of an organization itself may be multiple, then the short-term goal and sub goal of an organization are more likely to be multiple. These are exactly what people need to study. He pointed out that the problem would be simpler if the goals had the same degree of importance and could be combined in a simple way; but that was not the case, because they had different levels of importance and their achievements might not be easily measured. According to Seashore, the decision-making of managers should be based on the evaluation of business performance from various perspectives. It is impossible to maximize all objectives at the same time

Organizational structure can affect organizational performance [9]. They mainly study the economic measurement between organizational structure and organizational performance. And the economic measurement is not balanced scorecard. Here, performance is defined as the net present value of an organization's adoption of profitable innovations. Balanced scorecard is used as an indicator of economic measurement through the four dimensions of financial level, customer level, internal operation level, and learning/growth level. It mainly measures the income inequality caused by the principle of alternative compensation. The basic idea of this study is that the adaptability of an organization depends on the profitable innovation activities adopted by its members. This study shows that a large number of economic inequalities observed may be due to the positioning of individuals in the organizational structure, and the difference between human capital and innate ability may be the result of the position of individuals in the hierarchy, but the existence of the structure itself is an obvious resource inequality.

In addition, the factors that make up the organization but have nothing to do with individual characteristics (such as income, cost, etc.) also systematically affect the degree of inequality. Although the research does not explain the observed inequality in reality, it verifies the maxim "not what you know, but who you are". The research points out that the cause of economic inequality is rarely concerned in economics. Regardless of individual personality differences, the prevalence of hierarchy and organizational structure itself is the source of income inequality.

\section{The Relationship between BSC and Enterprise Organization}

\subsection{Performance Management}

Performance refers to the phased results achieved by the job responsibilities of the corresponding positions and the evaluable behavior performance in the process. The so-called performance management refers to the management method that 
motivates and helps employees to achieve excellent performance so as to achieve organizational goals on the basis of reaching a consensus between managers and employees on goals and how to achieve them. The purpose of performance management is to improve the company's performance by stimulating employees' enthusiasm and improving their abilities and qualities.

First of all, performance management should solve several problems:

1) There is a need for consensus on goals and how to achieve them.

2) Performance management is not a simple task management, it emphasizes communication, coaching and the improvement of employees' ability.

3) Performance management not only emphasizes result orientation, but also the process of achieving goals.

Performance management covers a lot of contents. The problems need to be solved as follows. How to determine effective goals? How to reach a consensus between managers and employees? How to guide employees towards the right goals? How to monitor the process of achieving goals? How to evaluate the achievement and improve the target performance? Performance in performance management is different from what many people usually understand as "performance". In performance management, we think that performance is a result first, that is, what has been done; secondly, the process, that is, what kind of behavior has been used; thirdly, the quality of performance itself. Therefore, performance appraisal is only a part of performance management. Performance management is a continuous business management loop process between managers and employees to achieve performance improvement. PDCA loop is adopted as a means (Figure 3).

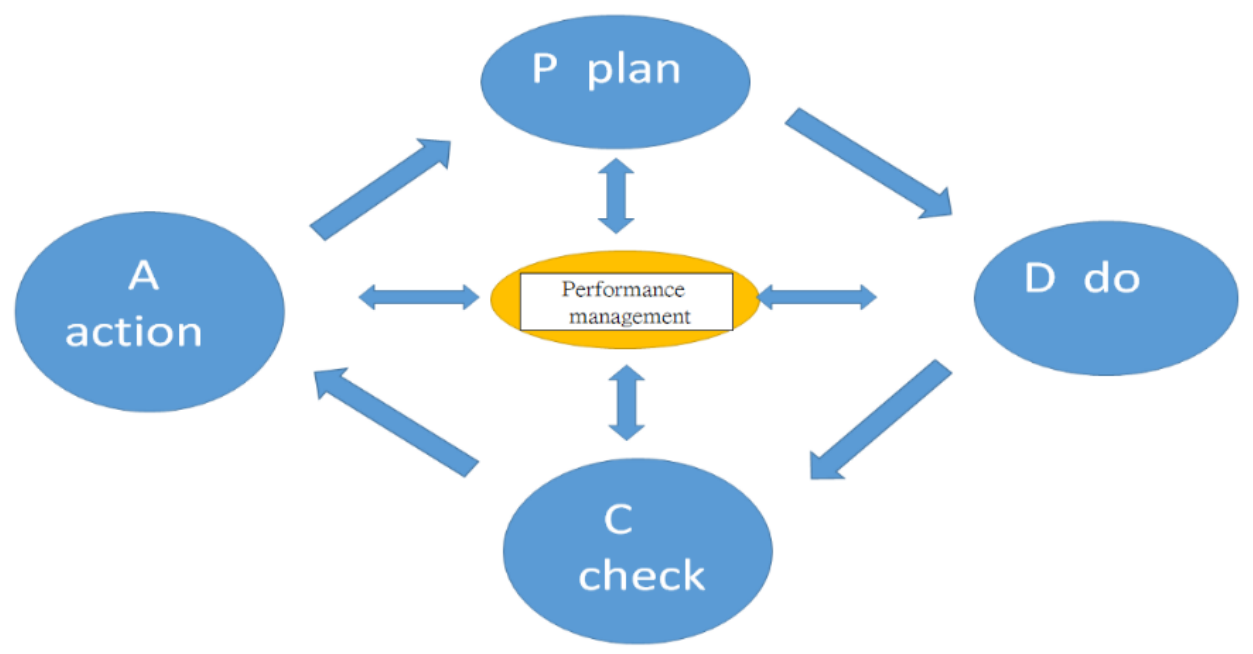

Figure 3: PDCA Loop Chart of Organizational Performance 


\subsection{Influencing Factors of Performance}

The main factors that affect performance are employee skills, external environment, internal conditions and incentive effect. Employee skills refer to the core abilities of employees, which are internal factors that can be improved after training and development; external environment refers to the factors that organizations and individuals are not controlled by the organization, which are objective factors that we cannot control at all; internal conditions refer to various resources that organizations and individuals need to carry out their work, which are also objective factors. To a certain extent, they can change the restriction of internal conditions; incentive effect refers to the initiative and enthusiasm of organizations and individuals to achieve their goals, and incentive effect is a subjective factor.

Among the four factors that affect performance, only the incentive effect is the most active factor. With the improvement of people's initiative and enthusiasm, the organization and employees will strive for the support of internal resources, while the skill level of the organization and employees will be gradually improved. Therefore, performance management is to stimulate people's initiative and enthusiasm through appropriate incentive mechanism, stimulate organizations and employees to strive for the improvement of internal conditions, improve the level of skills, and then improve individual and organizational performance. In addition to the above factors, the influencing factors of organizational performance are:

\subsection{Strategic Orientation}

The strategic orientation of an organization determines the scope of business, the customer groups it serves and the competitive strategy it adopts. These will affect the performance of the organization at the macro level, and the change of the strategic orientation of an organization will affect the organizational structure at the micro level. Purchasing organizational structure as the research object, is proposed the reasons of functional organizational structure change and how these changes happened [10]. It is found that environmental pressure will drive organizational change, but it is not the only factor that leads to organizational change. Organizational structure is affected by environment and strategy, and departmental organization which must be consistent with enterprise strategy and structure. It is necessary to consider not only the change of the whole structure of the enterprise, but also the function of the department. In terms of strategic orientation, successful enterprises generally have the following three characteristics.

\subsubsection{Access to Customers}

Some scholars believe that excellent organization is customer driven, which is characterized by taking customers as the most important stakeholders, and the main value of a successful organization is to meet the needs of customers. 


\subsubsection{Quick Response}

Rapid response means that an excellent organization can respond quickly to problems and opportunities. This requires organizations to constantly respond to new problems and opportunities in the market environment and within the organization under the changing business environment, so as to bring new impetus to the development of the organization.

\subsubsection{Clear Focus}

The organization needs to have clear priorities and goals. The goals should not be shifted from left to right. In other words, the organizational strategy should be sustained to a certain extent, and should not be transferred from the business that you are good at to other businesses.

\subsection{Senior Management}

Top management's mind and leadership style also have an important impact on organizational performance. According to bass, there are two types of Leadership: transactional leadership and transformational leadership. The so-called transactional leadership refers to the relationship between leaders and subordinates based on a series of transactions and implied contracts. This type of leader leads subordinates in the way of reward. When subordinates complete specific tasks, they give promises and rewards. The whole process is like a transaction. The so-called transformational leadership refers to that leaders promote the improvement of performance and the change of the whole organization by changing the motivation and values of subordinates, such as upgrading the level of need, transcending self interest, etc.; transformational leadership involves four dimensions: charisma, motivation, personal care and intellectual stimulation. It is found that leadership style is closely related to organizational performance.

In the banking industry, transformational managers will gain more customer market share than transactional managers [11]. The impact of transformational leadership on organizational climate and financial performance [12]. Leadership behavior is mainly measured from two aspects: leader charm and providing vision. Organizational climate is measured from three aspects: organizational effectiveness, willingness to innovate and communication level. Financial performance is measured by two variables: net profit and controllable cost. Their research suggests that transformational leadership with charisma has a greater impact on organizational financial performance and organizational climate than structural and caring leadership. Transformational leadership with charisma can not only improve employee satisfaction and productivity, but also improve the effectiveness of the organization, strengthen the communication among members of the organization, stimulate employees' willingness to innovate, so that they have a stronger sense of responsibility, strive to improve the quality of work, and promote the improvement of financial performance of the organization. 


\subsection{Classification of Organizational Performance Indicators}

In order to ensure the comprehensiveness of information, when evaluating organizational performance, we should consider using a variety of indicators to measure the degree of completion of organizational goals, and focus on using some indicators, that is, to determine a larger weight. Therefore, first of all, indicators should be differentiated according to different standards and uses.

\subsubsection{Objectives and Means}

Some indicators represent the results or goals of the organization's business activities, while others are the conditions or means for the organization to achieve its goals. Generally speaking, the target index should occupy a larger weight in the index system, while the means index has a smaller relative weight.

\subsubsection{Time}

First of all, we should pay attention to whether the indicators look at the past, the present or the future. Secondly, the time span of indicators should be considered. For enterprises with large changes in demand, long-term and short-term indicators are often very different.

\subsubsection{Hard Index and Soft Index}

Hard indicators are usually quantitative indicators, which can objectively reflect the tangible aspects of organizational performance. However, the hard indicators are mostly applicable to the short-term objectives of the organization, which can not reflect such situations as customers' recognition of the enterprise and employees' satisfaction. These are usually measured by the soft indicators, so sometimes the soft indicators may be more suitable for evaluating the business activities of the enterprise.

\subsubsection{Value Judgment}

Many indicators are high or low, usually there is no unified standard, different people's value judgments are often different. At this time, the internal and external environment of the organization and the change rule of the index itself should be comprehensively weighed to determine its applicability.

\subsection{Hierarchy of Indicators}

With specific indicators, in order to effectively evaluate organizational performance, we should give different weights to various indicators. Due to the different priorities and importance of various indicators, their weights should also be different. According to the American scholar Seashore, there are three different levels to evaluate an organization's performance (Figure 4): One is the realization of the organization's overall long-term goals; the other is the short-term business performance measured by a number of short-term indicators. These short-term goals will determine the organization's final business situation; the third is the current 
business situation reflected by the low-level indicator group. Some indicators can reflect the progress towards the final goal in time or the possibility of success. Seashore vividly combines the standards of measuring organizational performance into a pyramid shaped hierarchical system [7]. The ultimate goals are at the top of the tower, which reflect the degree of effective use of environmental resources and opportunities to achieve their long-term and formal goals; at the middle of the pyramid are some intermediate goals, which affect the short-term operating efficiency of the organization, which are also the results of the enterprise's pursuit; at the bottom of the tower some evaluation standards are for the current activities of the organization, which generally reflect the preconditions for the smooth and full realization of the intermediate goals.

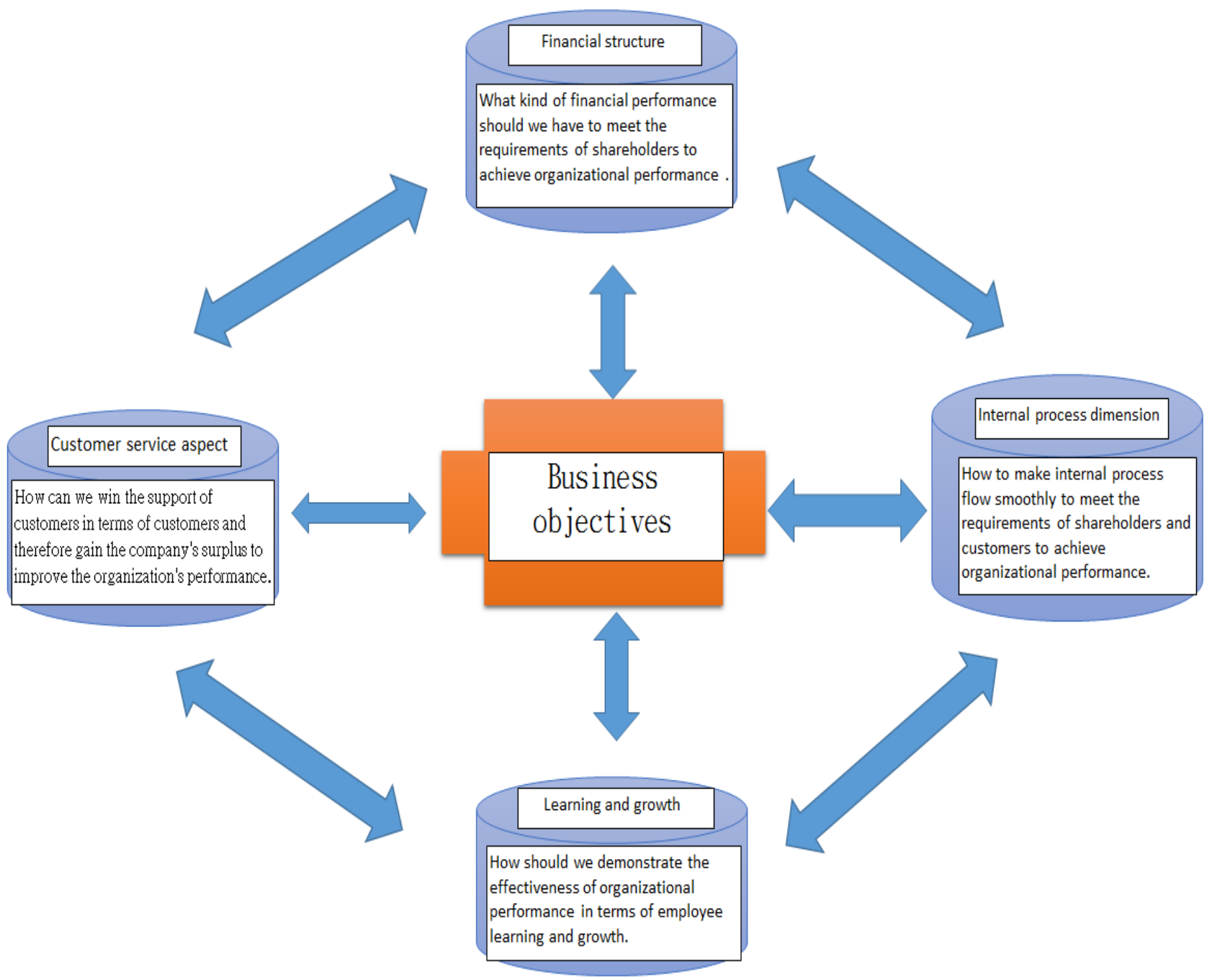

Figure 4: The Relationship between Business Objectives and Balanced Scorecard (BSC) 


\section{Using BSC to Establish Organizational Performance Management Structure \\ 4.1 Organizational performance}

Organizational performance is a comprehensive concept of the ability to use organizational resources and the degree to which expected goals are achieved. Organizational performance must be closely linked with reward and punishment mechanism [13]. Organizational culture has an interaction between organizational commitment and organizational performance; that is, organizational culture not only has a direct positive impact on organizational performance, but also indirectly affects organizational performance of employees' organizational commitment [14]. The culture of focusing on organizational processes and knowledge training is extremely important, and organizational culture and human resource management are significantly related to organizational performance [15].

However, there are many factors that affect organizational performance, and the sensitivity and adaptability of organizational leaders to social change issues are related to the degree of mission achievement, and the effect of leadership motivation also affects the improvement of organizational performance [16]. As a result, organizational performance has the characteristics of mutable, comprehensive, divergent, transitional and complex, so we should start from the perspective of target effect, action effect and result effect, and comprehensively use strategic thinking to create and extend performance [17]. Continuous evaluation of organizational performance is the key to the sustainable progress of an organization, while the balanced scorecard provides a comprehensive review framework of strategy and performance consistency standards, corrects the shortcomings of the traditional lack of strategic thinking, focusing on short-term perspectives, lack of flexibility and lack of information quality, so as to help managers improve decisionmaking quality from a broader perspective [18].

\subsection{Content of BSC and Organizational Performance Management Framework}

\subsubsection{Content Framework of BSC}

Balanced scorecard from finance, customer, internal process, learning and growth manages and evaluates the performance of an enterprise organization from five interrelated perspectives. From financial perspective, we adopt income, profit, return on evaluation of assets and economic value added (EVA). Other indicators reflect the organizational efficiency of enterprises to create different values for shareholders. From customer perspective, we use the adoption of customer satisfaction, customer loyalty, new customer growth rate, customer's profit contribution and other indicators to reflect how to provide customers with the products they need.

Regarding service attitude, the perspective of internal process is through the adoption of enterprise internal value chain. Indicators such as core quality activities and quality control circle support activities reflect the operation process of the 
enterprise. What needs to be improved? Learning and growth perspectives through adopters Indicators such as retention rate, employee productivity and employee satisfaction reflect the enterprise Employees adapt to the changing economic environment and the continuous improvement of professional and technical capabilities.

\subsubsection{Strategic Management Functional Framework of BSC}

FORTUNE Magazine (1999, June 21) points out that less than $10 \%$ of the right corporate strategies are right implementation by Ram Charna and Geofery Colvin. The case study found that enterprise failure is rarely due to the lack of strategy, and $70 \%$ is due to poor strategy implementation and unclear performance indicators. Research results show four barriers are:

1) vision barrier, only $5 \%$ of employees understand the corporate strategy;

2) staff barriers, only $25 \%$ of business managers will staff incentives and corporate policies,

3) slightly related resource barriers, $60 \%$ of enterprises mismatching budget with strategy,

4) management barriers, $85 \%$ of enterprises spending a great deal of time for discussing strategies. Less.

The emergence of balanced scorecard has broken four barriers, transformed to the four strategic management. The management function provides a good framework for policy execution (Figure 5).

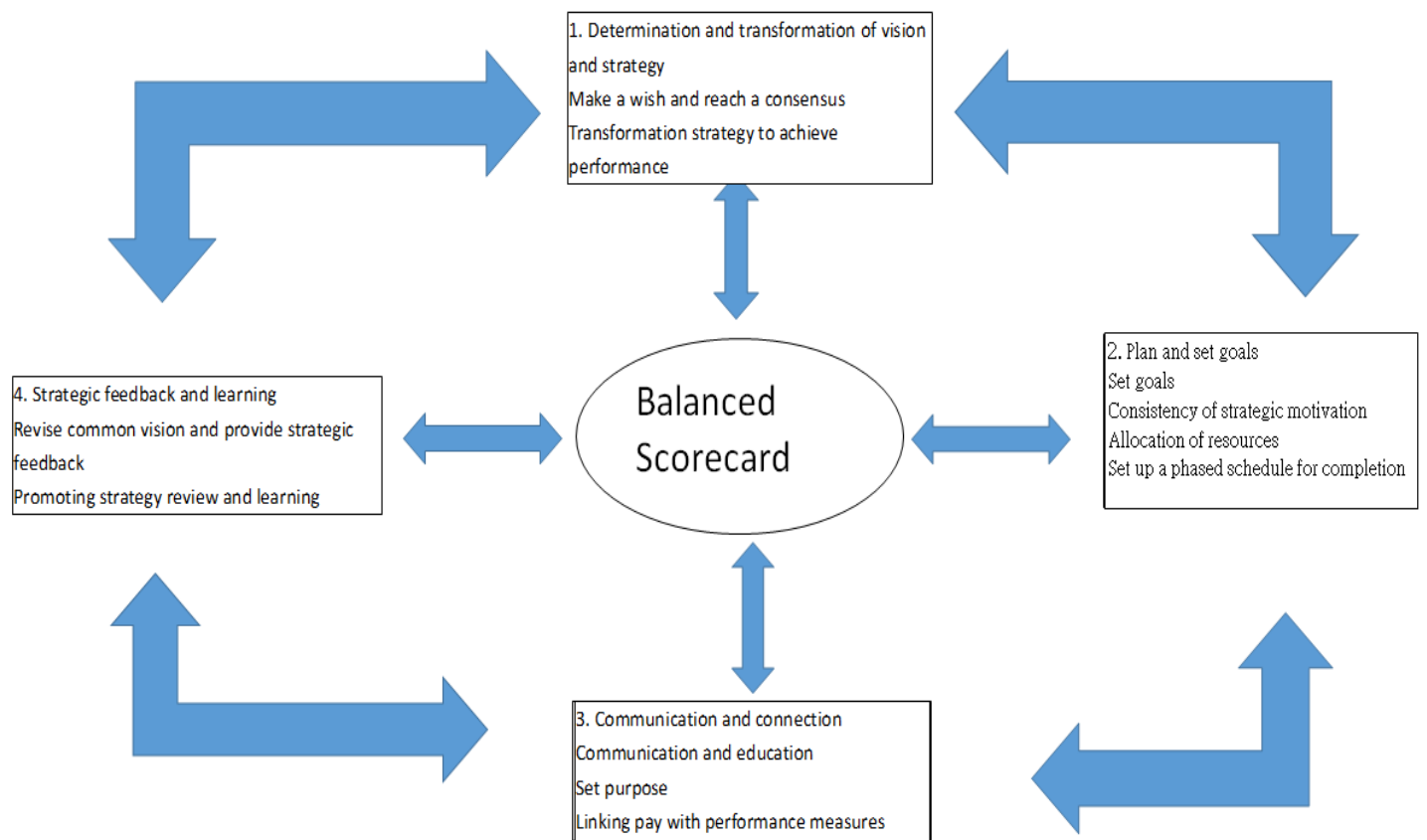

Figure 5: Take the Balanced Scorecard as a Strategic Framework for Action 


\subsection{The Relationship between BSC and Organizational Performance Evaluation Indicators}

From the company's common vision, the company's business strategy is produced, then the company's business strategy is transformed into four dimensions of the balanced scorecard, and then the four dimensions of the balanced scorecard are used to set up organizational performance evaluation indicators, which are fed back to the company's common vision, and therefore, modified and adjusted to form a forced circle diagram (Figure 6).

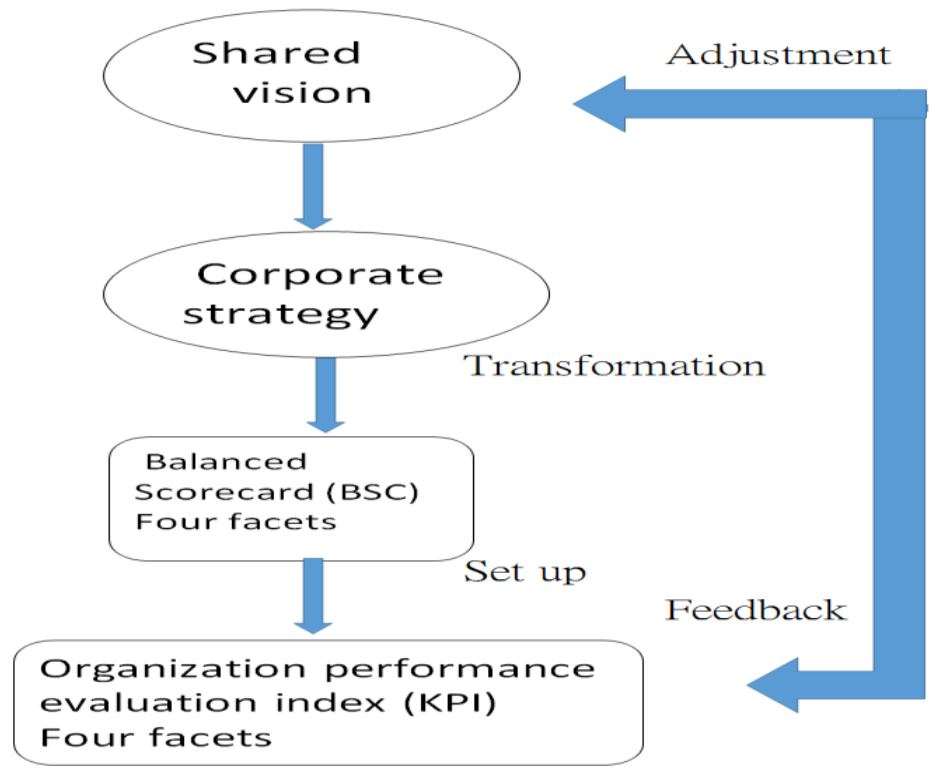

Figure 6: The Relationship between BSC and Organizational Performance Evaluation Indicators

\subsection{Design of Company Performance Management Scheme based on BSC}

\subsubsection{Basic Idea of BSC}

\subsubsection{Determining the four dimensions of BSC}

The balanced scorecard is composed of customer dimension, financial dimension, internal process dimension, learning and growth dimension.

\subsubsection{Attention and Publicity of Senior Leaders}

The design and implementation of the Balanced Scorecard involves all aspects of the enterprise, such as corporate culture, corporate strategy, organizational performance, resource utilization, internal process and management concept. If the senior leaders do not pay attention to and support, and the publicity of the enterprise is not enough, then the enthusiasm and investment intensity of employees will be 
reduced, and the implementation of the balanced scorecard is unlikely to succeed. Without the support and cooperation of senior leaders, the quality of balanced scorecard is just a fiction.

\subsubsection{Tailor Made with the Participation of All Employees}

Tailor made, with the participation of all employees, up and down communication, and annual revision of its strategic objectives, BSC only provides a basic conceptual framework, which must be tailored to the basic situation of the enterprise if the company wants to apply it, BSC involves all aspects of the development of the enterprise, and should design scientific indicators in line with the development of the enterprise and get good implementation results, BSC can not be separated from the enthusiasm and active participation of the whole staff; the indicator design of BSC needs to start from the top of the enterprise, given instructions from the top to the bottom, and finally getting feedback from the bottom to the top, communicating from the top to the bottom to reach the agreement of strategic objectives. In the process of implementation, it is also necessary to actively modify the implementation effect and the actual development of the enterprise every year, so as to obtain a scientific development strategic performance management tool.

\subsubsection{Analysis of Key factors Affecting the Success of Company's Strategy}

To implement the balanced scorecard, the key is to analyze the key factors for the success of the enterprise according to the strategic goal planning.

\subsubsection{Creating a Good External Image and Enhancing Brand Awareness}

For an enterprise, a good external image can bring good bonus points in terms of bank financing, commitment of old customers, and acceptance of new customers. It can also bring a good impact on the brand marketing of products with reliable quality, intangible influence on the acceptance of new projects, and a good external image, which can greatly enhance the brand's popularity and reputation.

\subsubsection{Manufacturing products to Meet Customer Needs, Improving Customer Satisfaction and Return Rate}

In terms of manufactured products, the products required by customers are the products that meet the design requirements and various functions with short delivery time, good quality assurance, safety and reliability, and low price. In the process of order acceptance, manufacturing process, and after-sales maintenance and warranty, the products continuously meet the needs of customers and improve customer satisfaction are the key factors necessary for a successful enterprise.

\subsubsection{Strengthening Value Creation of Internal Processes and Improving Cost Management}

Due to the continuous expansion of the market scale, the continuous growth of the company's capital stock, the vigorous development of investment business, and the 
continuous enhancement of the strength of the enterprise, the company is inseparable from the importance attached by each leading team to the informationbased development of the enterprise. The application of information means such as integrated implementation information system developed independently by the company creates value for the internal process of the enterprise

The integration of "standardization" and "information" emphasized by the company has injected new vitality into improving the cost management of the company. But "standardization" and "information" are not immutable. With the development of new forms of the company and the change of internal and external environment, the internal process of information still needs to be constantly revised. Paying attention to the value creation of the internal process and improving the cost management level are another key success factors for the connotative development of an enterprise.

\subsubsection{Strengthening the Ability of Marketing and Increasing Market Share} In modern society, the competition among enterprises is fierce, and the marketing ability directly reflects the survival of enterprises. For enterprises, marketing is the main work. Only by strengthening the marketing ability and increasing the market share, can they stand in the fierce market competition.

\subsubsection{Carrying forward the Benign Competitive Culture and Developing Professional Talents}

It is the company's concept of talent training and development to carry forward the benign competitive culture of sustainable inheritance, actively cultivate the spirit of "bold, energetic and smart" and "responsible, difficult and dangerous" of all employees, and ensure the endogenous power source of enterprise development. To this end, we should adhere to the principle of enterprise and employees' progress and development together, adhere to the principle that human resources are the first resource of the enterprise, focusing on the individual employees, implement the human-oriented management of "career retention, emotion retention and treatment retention", and improve the talent attraction and team cohesion through professional planning, education and training and performance management, as well as to achieve the effective unity of personal goals and organizational goals. 

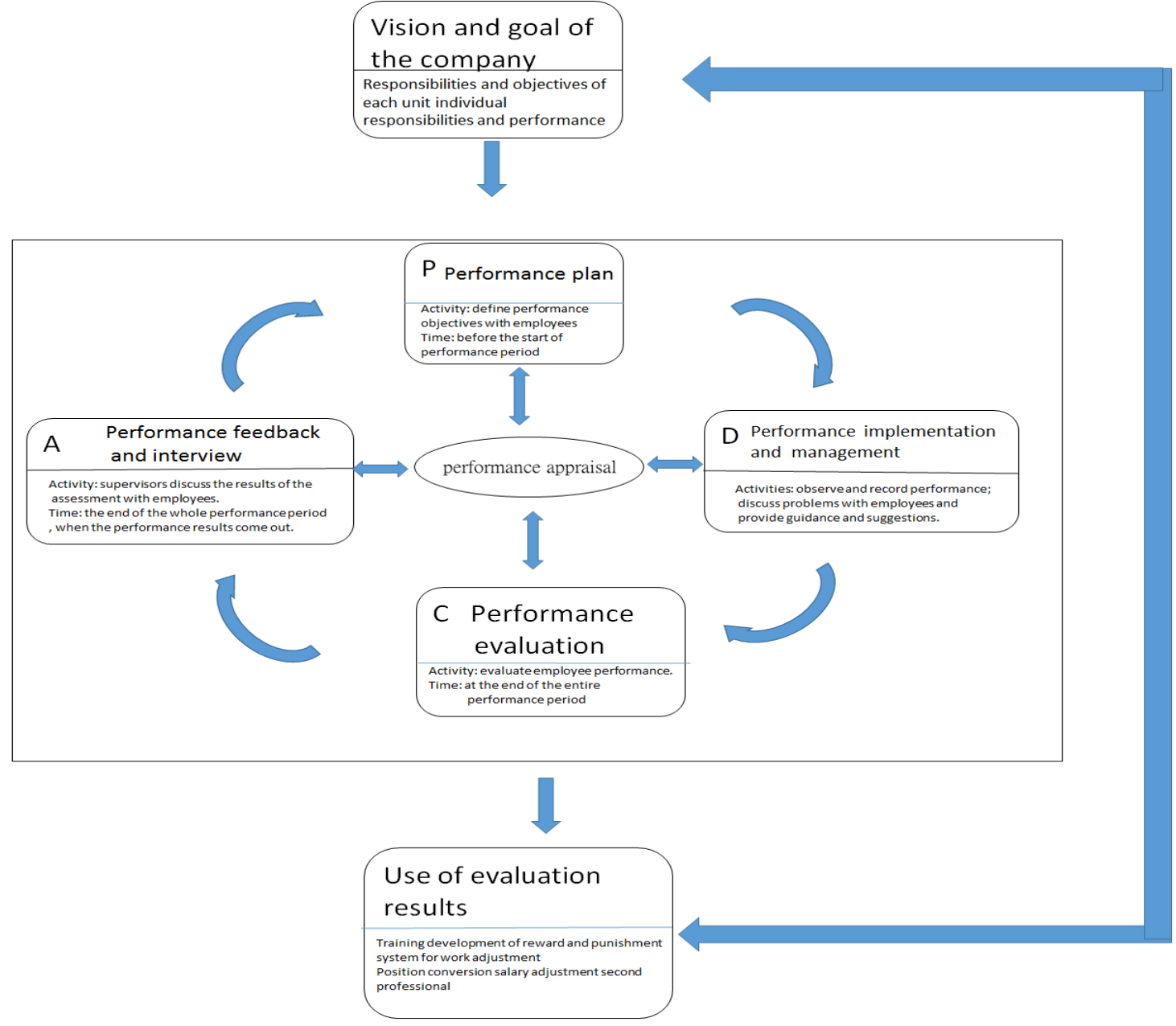

Figure 7: Performance Management PDCA

\section{How to Use BSC to Make the Organizational Performance Appraisal Form}

Performance evaluation index design of the company. According to the company's strategic planning, the analysis of key factors affecting the success of the strategy and the Balanced Scorecard theory, the following assessment indicators are designed (Figure 7).

\subsection{Financial Dimension Indicators}

Financial dimension is an important goal of connotation development. The specific measures and goals are:

1) to improve profitability. Design indicators: EVA of economic added value, return on net assets (return on invested capital), average profit rate of 
settlement project, proportion of total cost in operating revenue and total profit.

2) to maintain a certain level of repayment and reduce financial risks. Design index: asset liability ratio.

3) to maintain a certain level of efficiency of assets to ensure the ability of assets to continuously generate profits and cash. Design indicators: turnover rate of total assets, proportion of operating net cash flow to operating income, and investment recovery.

4) Due to the continuous expansion of the company. Design index: total asset growth Rate, operating revenue and total settlement amount shall be included.

\subsection{Customer Dimension Indicator}

The customer dimension pursues the brand service of keeping improving. Specific measures and objectives:

1) to improve customer satisfaction from product order acceptance, manufacturing and perfect after-sales service. Design indicators: customer satisfaction survey of projects under construction (delivery date, quality, management), customer satisfaction survey of after-sales service.

2) adhere to the development direction of multiple integration and develop new customer resources. Design indicators: proportion of new customers, proportion of strategic customers and market concentration.

3) to strengthen resource management and improve the competitiveness of products and services. Design index: signing rate of suppliers and cost reduction rate of centralized purchase materials.

\subsection{Internal Process Dimension Indicators}

The internal process dimension promotes the ability of information value creation, comprehensively implements the quality control circle management, and keeps the innovation spirit of keeping pace with the times. Specific measures and objectives:

1) to strengthen the standardization and information of internal processes, and improve the level of information application. Design indicators: the completion rate of the company's information promotion plan and the comprehensive management evaluation of the enterprise.

2) to integrate multi-link resources, focus on different professional collaboration, and strive to improve excellence and comprehensive services. Design indicators: product project lean internal process standardization, implementation rate of information promotion plan, utilization rate of information management tools.

3) to promote innovation in ideas, organizations, businesses, systems and business models. Design Indicators: innovation and innovation mode of business model, suggestions and adoption of system, research and development of special projects.

4) to expand new businesses and build a platform for innovation and 
development.

Design index: system design and evaluation of new business management mode.

\subsection{Indicators of Learning and Growth Dimensions}

In the dimension of learning and development, we should carry forward the virtuous competitive culture of sustainable inheritance and build a development platform shared by all staff. The specific measures and objectives are as follows:

1) to cultivate the spirit of "courage, energy, spirit" and "responsibility, difficulty and danger" of all staff. Design indicators: internal training instructor system and implementation plan completion rate, employee KPI assessment adaptability and effectiveness evaluation.

2) to increase the professional team to build a professional team. Design indicators: professional team building and professional team evaluation.

3) Professional planning, education and training, and performance management, improve talent attraction and team cohesion, and achieve the effective unity of personal goals and organizational goals.

Design indicators: annual training time of employees, retention rate of key employees, promotion rate of employees, achievement rate of job qualifications, working status of employees and salary satisfaction rate.

\section{Conclusion}

At the beginning, the application of balanced scorecard is only a simple performance evaluation system. After more than ten years of development, it has become a strategy management system of strategy and measurement. Structurally speaking, the balanced scorecard is a management system based on vision and strategy, which measures how to practice strategy on four dimensions.

From the whole development process, we can know from four papers published by Norton and Kaplan, including "practice of Balanced Scorecard" (1993), "practice of Balanced Scorecard in FMC: Interview with Brady" (1993), "Application of Balanced Scorecard in strategic management system" (1996). And strategy core organization to effectively implement the corporate strategy with balanced scorecard (2001), respectively, stating that balanced scorecard examines the enterprise from four perspectives; how BSC links strategy and performance measurement system in different organizations. With the BSC as the strategic measurement system, a dozen measurement indicators are set according to the design to make the short-term operational performance measurement indicators consistent with the long-term strategy. The BSC has evolved from the improved performance measurement system to a strategic measurement system architecture. How to use the BSC to successfully implement the organization's strategy.

In the 21 st century with dynamic and high competition, the traditional performance evaluation system has been unable to meet the strategic needs, and the balanced scorecard is based on strategy rather than control. It is not only used to clarify and communicate strategies, but also to manage strategies. Therefore, the balanced 
scorecard has evolved from a revised measurement system to a core strategic management system. Most of the early BSC studies were targeted at large enterprises. Until Chow, Haddad, and Williamson's article (1997), it was first mentioned that balanced scorecard can also be used in small and medium enterprises [19]. Based on this article, we really studied how to use balanced scorecard system for small and medium-sized enterprises. It not only puts forward how to construct the guidelines of Balanced Scorecard process for SMEs, but also discusses that balanced scorecard will bring benefits to SMEs.

\section{References}

[1] Kaplan, R. S. and Norton, D. P. (1996), The Balanced Scorecard: Translating Strategy into Action, Boston: HBS Press.

[2] Kaplan, R. S. and Norton, D. P. (2004), Strategy Maps: Converting Intangible Assets into Tangible Outcomes, Boston, HBS Press.

[3] Kaplan, R.S. and Norton, D. P. (2006), Alignment: Using the Balanced Scorecard to Create Corporate Synergies, Harvard Business School Press, Boston, M.A.

[4] Burney, L. L. and Swanson, N. J. (2010), "The Relationship between Balanced Scorecard Characteristics and Managers' Job Satisfaction,"Journal of Managerial Issues, 22(2), 166-181.

[5] Wu. A. (2005), "The Integration between Balanced Scorecard and Intellectual Capital," Journal of Intellectual Capital, 6(2), 267-284.

[6] Lucianetti, L. (2010), "The Impact of the Strategy Maps on Balanced Scorecard Performance," International Journal of Business Performance Management, 12(1), 21-36.

[7] Seashore, S. E. and Yuchtman, E. (1967), "Factorial Analysis of Organizational Performance,"Administrative Science Quarterly, 12, 377-395.

[8] Kaplan, R. S. and Norton, D. P. (1992), "The Balanced Scorecard: Measures that Drive Performance," Harvard Business Review, Jan-Feb, 71-79.

[9] DeCanio, S. J., Dibble, C., and Amir-Atefi, K. (2000), "The Importance of Organizational Structure for the Adoption of Innovations," Management Science, 46(10), 1285-1299.

[10] Johnson, P. F. and Lenders, M. R. (2001), "The Supply Organizational Structure Dilemma," Journal of Supply Chain Management, 6, 4-11.

[11] Steyrer, J. and Mende, M. (1994), "Transformational Leadership: The Local Market Success of Austrian Branch Bank Managers and Training Applications," the Meeting of the International Congress of Applied Psychology, Madrid, Spain.

[12] Koene, B. A. S., Vogelaar, A. L. W. and Soeters, J. L. (2002), "Leadership Effects on Organizational Climate and Financial Performance: Local Leadership Effect in Chain Organizations," The Leadership Quarterly, 13, 193-215. 
[13] Mao, T. and Hu, T. (2010), "Stochastic Properties of INID Progressively: Type-II Censored Order Statistics," Journal of Multivariate Analysis, 101(6), 1493-1500. p. 100 - 122 ISSN 1808-2386

[14] Nikpour, A. (2017), "The Impact of Organizational Culture on Organizational Performance: The Mediating Role of Employee's Organizational Commitment," International Journal of Organizational Leadership, 6, 65-72.

[15] Santos, N. de M., Bronzo, M., de Oliveira, M. P. V. and de Resende, P. T. V. (2014), "Organizational Culture, Organizational Structure and Human Resource Management as Bases for Business Process Orientation and their Impacts on Organizational Performance," Brazilian Business Review, 111(3), 100-122.

[16] Boesen, T. (2000), "Creating Budget-Less Organizations with the Balanced Scorecard," HBS Balanced Scorecard Report (Nov/Dec).

[17] Wang, Yixin (2004), "The Case of BSC Application in University Libraries: National Taipei University," Accounting Research Monthly, 224, 150-155.

[18] Shahin, A., Shabani Naftchali, J. and Khazaei Pool, J. (2014), "Developing a Model for the Influence of Perceived Organizational Climate on Organizational Citizenship Behaviour and Organizational Performance Based on Balanced Scorecard," International Journal of Productivity and Performance Management, 63(3), 290-307.

[19] Chow, C.W., Haddad, K.M. and Williamson, J.E. (1997), "Applying the Balanced Scorecard to Small Companies," Management Accounting, 79, 2127. 